\title{
The Application of the New Stabilizer in Treating the Viscosity Loss of Sewage Polymer Solution
}

\author{
Sihao Jiang \\ No.5 Production Plant of Daqing Oil Field
}

Keywords: stabilizer, polymer solution, loss rate of viscosity

\begin{abstract}
The using of sewage to confecting polymer solution is the inevitable choice of oilfield development and environmental protection, as Daqing oilfield produced a lot of sewage. With the increase of quantity of bacteria and population. We did experiment in the laboratory and analysised the mechanism of the new stabilizer. The results show that the new stabilize can effectively inhibit the growth of bacteria in sewage. The main mechanism is the complexation, antibacterial effect, and inhibition of carbon and oxygen free radical of the stabilizer.
\end{abstract}

With the industrialization scale of polymer flooding expanding continuously, fresh water resources become increasingly tense and produced sewage is short of economic and effective treatment method, which brings great pressure on oil production and environmental protection. Therefore, the preparation process of compounding with clean water and diluting with sewage is used in the polymer flooding industrial area. The sewage used to diluting has high salinity, which contains a lot of bacteria, sulfate reducing bacteria, saprophytic bacteria, and iron bacteria. $\mathrm{Fe}^{2+}$ and $\mathrm{S}^{2-}$, the decomposition products of bacteria, produce oxygen free radicals when combined with $\mathrm{O}^{2}$. The oxygen free radicals lead to the degradation of the polymer and the decrease of viscosity. In order to solve the problem of viscosity loss during the compounding and injecting process, we carried out laboratory evaluation experiment and field test of the new polymer viscosity stabilizer, which has achieved remarkable results.

\section{The Mechanism of Action of the Polymer Viscosity Stabilizer}

The mechanism of polymer viscosity stabilizer mainly through metal ion complexation, bacterial inhibition, inhibition of carbon, oxygen free radical action, so as to reduce the effect of polymer viscosity loss rate.

\section{Complexation.}

In addition to inhibit the degradation of the polymer effectively, making the partially hydrolyzed linear polyacrylamide molecular unfolding in water is most important to keep the maximum size of the fluid mechanics, in order to make the polyacrylamide's viscosity to have a high reserved viscosity ratio. The metal cation has great effect on the unfolding of the linear polyacrylamide polymer, as the result of the exist of $\mathrm{Ca}^{2+}, \mathrm{Mg}^{2+}, \mathrm{Fe}^{3+}$ and $\mathrm{Fe}^{+}$in the polymer solution, which leading to the coiling of the polymer and the declining of the viscosity. The complexing agent in the stabilizer can effectively complex the high order metal ion, consequently, eliminate the influence of metal ion on the viscosity of polymer.

\section{Antibacterial effect.}

There is a lot of bacteria, such as sulfate reducing bacteria (SRB), iron bacteria (IB) and saprophytic bacteria (TGB), which have great destructive effect on the molecular chains of the polymer, resulting the poor stability of viscosity of polymer solution. The biological inhibitors in the new stabilizer can make the sulfate reducing bacteria and other bacteria in the sewage suffocation, thus to improve the viscosity retention rate.

\section{Inhibiting Effect of the Carbon and Oxygen Free Radical.}

At $45^{\circ} \mathrm{C}$ of reservoir temperature, the polymer thermal decomposition by heating, and generate carbon based radicals. The radicals can live enough long to cause the occurrence of ageing phenomenon, such as polymer molecular bond breaking, and then lead to the decline of the viscosity 
of polymer solution in aerobic or anaerobic condition. When added into the sewage, the stabilizer captures and inhibits the generation of carbon radicals, and inhibits the thermal degradation caused by the carbon radicals itself. On the other hand, it reduces the chance for the carbon radicals to generate peroxy radicals by further oxidation, and declines the pressure of capturing peroxy radicals whereafter, so as to stable the viscosity.

\section{The Results of the Laboratory Evaluation Experiment of the New Polymer Viscosity Stabilizer}

\section{Control of Sewage Bacteria by the New Polymer Viscosity Stabilizer.}

Add the new polymer viscosity stabilizer in to sewage and cultivate it for $7 \mathrm{~d}$ at $45^{\circ} \mathrm{C}$. Then test the number of bacteria in the sewage.

Tab1 Comparison of the Bacteria in the Sewage

\begin{tabular}{|c|c|c|c|c|c|c|c|c|}
\hline \multirow{2}{*}{ Number } & \multirow{2}{*}{ Sample } & $\begin{array}{c}\text { The } \\
\text { Concentration Of } \\
\text { Stabilizers(mg/L) }\end{array}$ & Growth Index & $\begin{array}{c}\text { Microbial } \\
\text { Content }\end{array}$ & Growth Index & $\begin{array}{c}\text { Microbial } \\
\text { Content }\end{array}$ & Growth Index & $\begin{array}{c}\text { Microbial } \\
\text { Content }\end{array}$ \\
\hline 1 & \multirow{2}{*}{ Sewage } & 0 & $311 \times 10^{4}$ & $7.5 \times 10^{4}$ & $333 \times 10^{2}$ & $1.4 \times 10^{4}$ & $331 \times 10^{4}$ & $7.5 \times 10^{5}$ \\
\cline { 3 - 8 } 2 & 100 & 000 & 0 & 000 & 0 & 000 & 0 \\
\hline
\end{tabular}

The experimental data shows that the new polymer viscosity stabilizer can effectively inhibit the growth of the bacteria in sewage, resulting in the elimination of the oxygen free radicals, which produced by the combination of the $\mathrm{Fe}^{2+}, \mathrm{S}^{2-}$ (decomposition product of the bacteria) and $\mathrm{O}^{2}$.

The Laboratory Evaluation Experiment of the Viscosity Stability.

Compound polymer solution with concentration of $5000 \mathrm{mg} / \mathrm{L}$, using clear water. Then dilute the solution to concentration of $1600 \mathrm{mg} / \mathrm{L}$, using aerated sewage. Seal the polymer solution with different concentrations of the new stabilizers into ampoules bottles at $45^{\circ} \mathrm{C}$. Test the effection of stabilizer on polymer stability.

Tab 2 The Effection of Stabilizer on Stability of the Viscosity of Polymer Solution Diluted by Sewage(mPa.s)

\begin{tabular}{|c|c|c|c|c|c|c|c|c|c|}
\hline \multirow[b]{2}{*}{ Polymer Type } & \multirow{2}{*}{$\begin{array}{c}\text { The } \\
\text { Concentration } \\
\text { Of Stabilizers } \\
(\mathrm{mg} / \mathrm{L})\end{array}$} & \multicolumn{7}{|c|}{ Viscosity(mPa.s) } & \multirow{2}{*}{$\begin{array}{l}\text { The Retention } \\
\text { Rate Of } \\
\text { Viscosity After } \\
60 \mathrm{~d}\end{array}$} \\
\hline & & $\begin{array}{c}\text { Early } \\
\text { Viscosity }\end{array}$ & $2 \mathrm{~h}$ & $1 d$ & $5 d$ & $10 \mathrm{~d}$ & $30 \mathrm{~d}$ & $60 d$ & \\
\hline \multirow{3}{*}{$\begin{array}{l}\text { Molecular Weight } \\
\text { Of } 19 \text { Million } \\
\text { (Concentration of } \\
1600 \mathrm{mg} / \mathrm{L})\end{array}$} & 0 & 48.7 & 45.3 & 39.4 & 34.6 & 28.1 & 22.7 & 19.0 & 39.0 \\
\hline & 100 & 49.7 & 49.1 & 48.9 & 48.7 & 48.7 & 48.5 & 48.5 & 97.6 \\
\hline & 150 & 50.9 & 50.4 & 50.2 & 50.1 & 50.0 & 49.9 & 49.9 & 98.0 \\
\hline \multirow{3}{*}{$\begin{array}{l}\text { Molecular Weight } \\
\text { Of } 23 \text { Million } \\
\text { (Concentration of } \\
1600 \mathrm{mg} / \mathrm{L})\end{array}$} & 0 & 53.9 & 50.1 & 47.8 & 42.1 & 38.7 & 29.6 & 21.6 & 40.1 \\
\hline & 100 & 54.9 & 54.4 & 54.1 & 54.0 & 53.9 & 53.9 & 53.9 & 98.2 \\
\hline & 150 & 55.3 & 54.7 & 54.5 & 54.5 & 54.4 & 54.4 & 54.4 & 98.4 \\
\hline
\end{tabular}

The laboratory test data shows that the concentration of the new stabilizer is $100 \mathrm{mg} / \mathrm{L}$. In the initial 2 hours, both the viscosity retention rate of the middle and the high molecule polymer was about $99 \%$. 60 days after the addition of stabilizer, the viscosity retention rate still above $97 \%$. 


\section{The Field Test}

\section{The Viscosity Change of Polymer at Pump Outlet for 90 Days.}

Sample from the pump outlet and wellhead and seal the samples from the wellhead into ampoules bottles at $45^{\circ} \mathrm{C}$. Test the viscosity of polymer after 90 days.

The field test was carried out of 6 wells at the injection station. The testing program was processed, which adopted the polymer of 23 million molecular weight, the injected concentration of $1200 \mathrm{mg} / \mathrm{L} \sim$ $1800 \mathrm{mg} / \mathrm{L}$, and dosing concentration of $100 \mathrm{mg} / \mathrm{L}$. The stabilizer was added into the single well mother liquid front the injection pump, and injected into the wellhead mixing with the polymer solution. Tested the viscosity of the sample, which sampled from the wellhead and after the pumb at the scene, and calculated the loss rate of viscosity. The result shows that the loss rate of viscosity is generally between $4.5 \sim 8.8 \%$, with an average of $6.7 \%$, in the 2 hours during which the polymer was transported from the injection pump to the wellhead. Testing the indoor samples from $2 \mathrm{~h}$ to 90 days, the change of the viscosity during the 90 days after the adding of stabilizer from the Tab 3 reveals that the decrease range of viscosity is very small, about $1.8 \%$. The viscosity retention rate is $40.0 \%$ after 60 days and 33.9\% after 90 days without viscosity stabilizer. Adding the new polymer viscosity stabilizer, the viscosity retention rate is $91.7 \%$ after 60 days and $91.1 \%$ after 90 days.

Tab 3 The Comparison Of Polymer Viscosity Changes At Wellhead(mPa.s)

\begin{tabular}{|c|c|c|c|c|c|c|c|c|c|}
\hline \multirow{3}{*}{$\begin{array}{c}\text { The } \\
\text { Concentratio } \\
\text { n Of } \\
\text { Stabilizers } \\
\text { (mg/L) }\end{array}$} & \multicolumn{8}{|c|}{ Viscosity(mPa.s) } & \multirow{3}{*}{$\begin{array}{c}\text { The } \\
\text { Concentration Of } \\
\text { Stabilizers after } \\
90 \mathrm{~d}(\%)\end{array}$} \\
\hline & \multicolumn{2}{|c|}{$\begin{array}{l}\text { Field Sampling } \\
\text { Detection }\end{array}$} & \multicolumn{6}{|c|}{ Indoor Sample Detection } & \\
\hline & $\begin{array}{c}\text { After } \\
\text { Pumping }\end{array}$ & Wellhead & $1 d$ & $10 \mathrm{~d}$ & $20 d$ & $30 \mathrm{~d}$ & $60 d$ & $90 d$ & \\
\hline 0 & 68.7 & 63.8 & 60.9 & 49.3 & 41.8 & 37.7 & 27.5 & 23.3 & 33.9 \\
\hline 100 & 69.9 & 64.9 & 64.8 & 64.7 & 64.7 & 64.6 & 64.1 & 63.7 & 91.1 \\
\hline
\end{tabular}

Combined with the viscosity stable experiment laboratory (Table 2), it can be identified that the viscosity loss of polymer caused by mechanical shear of the pipeline and the static mixer should be $5-7 \%$ from the pump to the wellhead, and other viscosity loss is caused by bacteria and water. The result that the viscosity retention rate of polymer is about $98 \%$ by adding viscosity stabilizer, shows that the consequence of adding drug at scene is consistent with the laboratory test.

\section{The Effect on Viscosity Loss Rate of Polymer by Line Cleaning.}

Rust and dirt would formed on the tube wall easily by long-term pipeline transporting of polymers and other chemical substances. So regular high-pressure water jet cleaning of pipeline is needed. The testing program was adopted at scene, which adopted the polymer of 23 million molecular weight, the injected concentration of $1600 \mathrm{mg} / \mathrm{L}$, and dosing concentration of $100 \mathrm{mg} / \mathrm{L}$. Clean the pipeline after injecting polymer. Test the sample from the wellhead for 60 days, comparing with the well without adding stabilizer.

As the Figure 1 shows, cleaning of the pipeline greatly affects the viscosity loss rate of polymer, because the residue of bacteria in the pipeline decreases the viscosity of the polymer gradually. But pipeline cleaning has almost no effect on the viscosity loss rate of polymer by adding stabilizer. The viscosity loss rate of polymer is $10.1 \%$, without adding the stabilizer, at the beginning after pipeline cleaning. Then the viscosity loss rate of polymer will gradually increase to $67.4 \%$ in the 60 days later. By adding the new polymer viscosity stabilizer, the viscosity loss rate of polymer is $7.41 \%$ at the beginning, then rises to $9.01 \%$ in the 60 days later by a slow upward trend. The viscosity loss rate of polymer reduces to the initial value and rises repeatedly after cleaning the pipeline again. The field test shows that the new polymer viscosity stabilizer only play an inhibitory effect on water quality and pipeline corrosion and other factors, without effecting on the initial mechanical loss. 


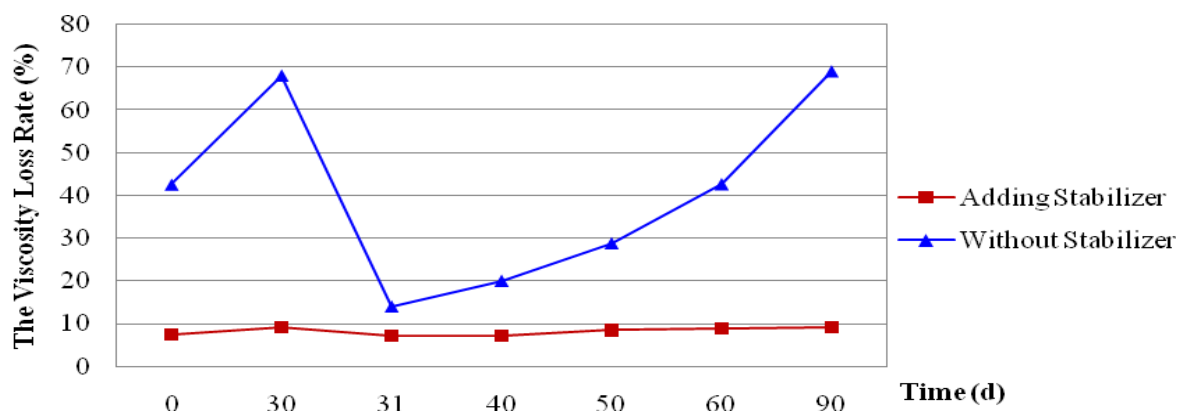

Fig. 1 The Effect On Viscosity Loss Rate Of Polymer By Line Cleaning

\section{Technical and Economic Analysis}

The price of the new polymer viscosity stabilizer is $3000 \mathrm{RMB}$ Yuan/Ton, and adding ratio of new polymer viscosity stabilizer and polymer powder is $1: 16$. So the cost increases only 187.5 yuan for 1 ton of polymer powder with the use of stabilizer. After 60 days of the injection of polymer, the viscosity retention rate of the polymer was $40 \%$ without adding stabilizer and $91.7 \%$ by adding stabilizer, which resulted in the save of the use of polymer for $50.1 \%$. The cost for per ton of polymer saved 8016 yuan, calculated according to 16000 yuan / ton. After 90 days of the injection of polymer, the viscosity retention rate of the polymer was $33.9 \%$ without adding stabilizer and $91.1 \%$ by adding stabilizer, which resulted in the save of the use of polymer for $57.2 \%$. The cost for per ton of polymer saved 9152 yuan, and the output ratio was $1: 48.8$. The polymer injected was fully utilized and the use value was effectively improved by the use of the new polymer viscosity stabilizer.

\section{Conclusion}

(1) The stabilizer can improve the stability of viscosity of polymer solution compouned by sewage.

(2) The stabilizer can effectively inhibit the growth of bacteria in sewage. Complexation, bacteriostasis and the inhibition of carbon and oxygen free radicals is the dominant mechanism of the stabilizer to reduce the viscosity loss rate of polymer.

(3) The polymer viscosity stabilizer only takes effect on water quality and pipeline corrosion and other factors, and takes no effect on the initial mechanical loss.

\section{Reference}

[1] Wu Mingming, Zhao Xiutai, Qiu Guangmin, et al. Study on viscosity stabilizers for flooding HPAM solution [J]. Oil Drilling \& Production Technology, 2005, 27 (3):38-40.

[2] Sun Lin, Pu Wanfen, Yang Huaijun. Study on viscosity stabilizers of the alkali / polymer two element compound viscosity stabilizer of flooding [J]. Drilling \& Production Technology, 2007, 30 (2):127-129

[3] Niu Jingang, Sun Gang, Fei. Experimental study on Preparation of polymer with sewage produced by oilfield [J]. Petroleum Geology and oilfield development In Daqing, 2001, 20 (2):17-19.

[4] Zhao Yuhua, Ye Yangfang. Sulfate reducing bacteria and its influencing factors [J]. Environmental Pollution \& Control, 1997, 19 (5):4143.

[5] Su Yanchang, Gao Feng, Shu Fangchun, et al. Study on Preparation of polymer with sewage [J]. Petroleum Geology and oilfield development In Daqing, 2003, 22 (6):44-47.

Bibliography: Jiang Sihao (1983), male, born in October 1983. Native place: Daqing, Heilongjiang. Holds a Bachelor's degree in petroleum engineering programs from Northeast Petroleum University in 2007. Mid-level engineer. A management worker of polymer flooding at The 
Management Department. Address: No.5 Production Plant of Daqing Oil Field in Daqing, Heilongjiang City Tel: 0459-4596650; Emai: jsihao@petrochina.com.cn. 